

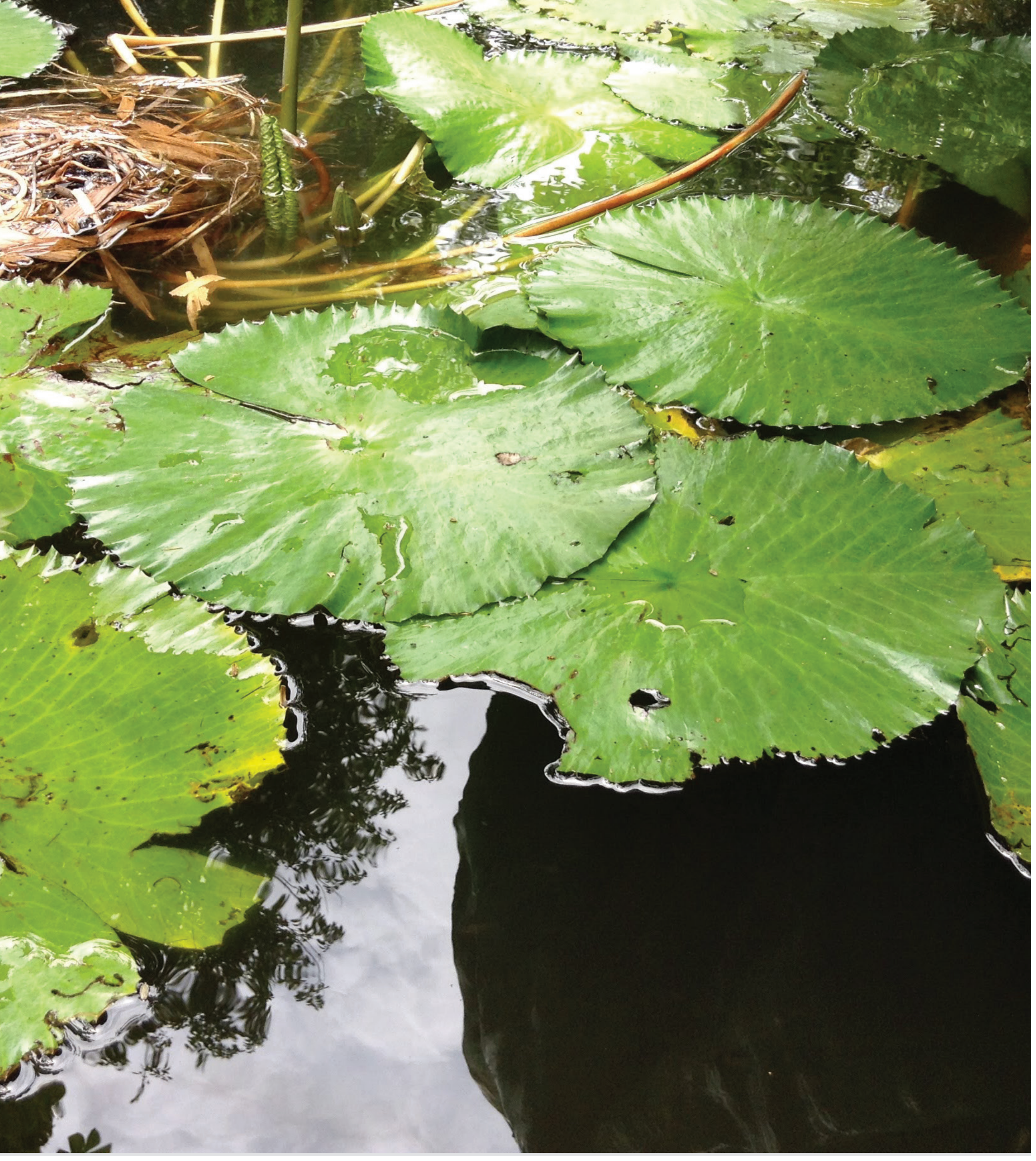




\section{Hasta la raíz: pedagogía para la reconstrucción del tejido social de familias víctimas del desarraigo}

Up to the Root:

Pedagogy for the

Reconstruction of

the Social Fabric of

Families Victims of

Uprooting
Até a raiz: Pedagogia

para a reconstrução

do tecido social das

famílias vítimas do

desenraizamento

\section{Marcela Cárdenas García*}

Fecha de recepción: 20-08-18

Fecha de aprobación: 30-10-18

\section{PARA CITAR ESTE ARTÍCULO}

Cárdenas, M. (2018). Hasta la raíz: pedagogía para la reconstrucción del tejido social de familias víctimas del desarraigo. Nodos y Nudos, 6(45), 45-51. doi: 10.17227/nyn.vol6.num45-8325 


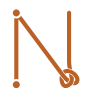

Volumen $6 \mathrm{~N} .{ }^{\circ} 45$ julio - diciembre de 2018 ISSN: 0122-4328 ISSN-E: 2619-6069 pp. 45-51

\section{RESUMEN}

En el presente artículo se visibilizan los hallazgos y conclusiones del ejercicio investigativo, realizado en la zona periférica de la localidad de Usaquén, de la ciudad de Bogotá, con un grupo de tres maestras de primera infancia que forman parte de la modalidad de Ámbito Familiar y que laboran con familias en condición de desplazamiento forzado. A partir del trabajo realizado por las maestras se analizó categorias como desplazamiento forzado, desarraigo, saber pedagógico y género. Se mostró cómo ellas transformaron su práctica pedagógica orientada en un principio al fortalecimiento del desarrollo integral de los niños y niñas, hacia la reconstrucción del tejido social de la crianza ejercida en medio de la guerra. Para ello utilizaron herramientas pedagógicas como la escucha y el diálogo cercano, la fotografía, la música, el trueque de objetos, los cuales no solo contribuyeron a sanar las heridas causadas por la guerra en las mujeres de este territorio, sino que fortalecieron el desarrollo integral de los niños y niñas, y la constr $n$ de su identidad. En conclusión, la investigación permitió caracterizar el trabajo de las maestras en espacios no convencionales, visibilizar sus dificultades, retos y saberes construidos para emprender esta labor y hacer un aporte para la construcción de una pedagogía para el posconflicto, que responde a las necesidades de una crianza marcada por la guerra.

Palabras clave: desarraigo; desplazamiento forzado; reconstrucción del tejido social; saberes

\section{ABSTRACT}

The following article intends to make visible the findings and conclusions of a research project, in the peripheral zone of the Usaquén locality in Bogotá, with a group of three early childhood teachers who are part of the Family Environment modality and who work with families in forced displacement condition. The work of the teachers carried out within the homes of these families was analyzed through categories such as forced displacement, uprooting, pedagogical knowledge among others, showing how the teachers transformed their pedagogical practice initially oriented to strengthening the integral development of children, towards the reconstruction of the social fabric of upbringing in the midst of war. For this they used pedagogical tools such as listening and close dialogue, photography, music, the exchange of objects, which not only helped to heal the wounds caused by the war in the women of this territory, but also strengthened the integral development of children and the construction of their identity. Therefore the research allowed to characterize the work of the teachers in unconventional spaces, to visualize their difficulties, challenges and knowledge built to undertake this work and to make a contribution for the construction of a pedagogy for the postconflict, which responds to the needs of an upbringing marked by war.

Keywords: uprooting; forced displacement; reconstruction of the social fabric; knowledge

\section{RESUMO}

Neste artigo, tornam-se visiveis as constatações e conclusões do exercício investigativo na zona periférica de Usaquén, na cidade de Bogotá, com um grupo de três professores da primeira infância que fazem parte da modalidade Ambiente Familiar e que eles trabalham com famílias em uma condição de deslocamento forçado. A partir do trabalho realizado pelos professores, foram analisadas categorias como deslocamento forçado, desenraizamento, conhecimento pedagógico e gênero. Mostrou-se como eles transformaram sua prática pedagógica orientada inicialmente para o fortalecimento do desenvolvimento integral das crianças, para reconstruir o tecido social da educação exercida no meio da guerra. Eles usaram ferramentas pedagógicas como a escuta e diálogo estreito, fotografia, música, a troca de objetos, que não só ajudaram a curar as feridas causadas pela guerra contra as mulheres deste território, mas fortaleceu o desenvolvimento global das crianças e a construção de sua identidade. Em conclusão, a pesquisa permitiu caracterizar o trabalho dos professores em espaços não convencionais, visualizar suas dificuldades, desafios e conhecimentos construídos para realizar este trabalho e contribuir para a construção de uma pedagogia para o pós-conflito, que responda às necessidades de uma educação marcada pela guerra.

Palavras-chave: desenraizamento; deslocamento forçado; reconstrução do tecido social; conhecimento 
Salir de allá fue duro, dejar la tierra en donde me crie y se crio él y el niño, fue jodido, pero no habia de otra, era eso o esperar a que lo mataran igual que a su hermano. Así nos doliera, él tenía razón, teniamos que buscar pa' dónde irnos, sin hacer tanta escama, sin decirle a nadie y cargando apenas lo necesario.

¡Quién iba a imaginar, profe, que íbamos a terminar en estas! Después de vivir tranquilos y de vivir en lo propio, pasamos a no tener nada y a deberle a todos, en medio de gente que ni nos voltea a mirar.

Relatos como el anterior, narrado por una campesina desplazada del Tolima, han llevado a Colombia a ubicarse como el segundo país del mundo con mayor cantidad de desplazados internos, al totalizar 6213989 víctimas por este flagelo, solo superado por Siria con 7600000 refugiados ( $\left.\mathrm{CNMH}_{1} 2015\right)$.

Asi pues, en nuestro pais son cada vez más las víctimas del desplazamiento forzado que huyen de sus tierras, con la añoranza de sepultar los malos momentos y comenzar de nuevo. Sin embargo, entran en un absurdo círculo vicioso, pues como se afirma en el más reciente informe sobre desplazamiento forzado en Colombia, publicado por el Centro Nacional de Memoria Histórica ( $\mathrm{CNMH}_{1}$ 2015) las dinámicas de violencia de los lugares de origen a los lugares de llegada son las mismas, pues el desplazamiento forzado arrastra consigo la violencia y la pobreza de la que se huye.

Ejemplo de lo anterior es la situación vivida en Bogotá, por la mayoría de familias que habitan en los barrios Lomitas, Serrezuela y Mirador, en la periferia de la localidad de Usaquén. Familias que, como resultado de la violencia generada por grupos armados, la explotación de la tierra o simplemente por la idea de salir de la pobreza, viven un presente marcado por el desarraigo.

Este desarraigo, como menciona da como resultado, cambios forzados en la estructura social, lo cual implica rupturas, pérdidas, dolor y mucho sufrimiento, que perviven en la memoria de cada miembro de esa familia", que ve con impotencia la desintegración de su hogar (Castaño, 2004).

Infortunadamente, cuando el conjunto de caracteristicas que singularizan una persona y su relación con el mundo que le rodea, se modifican de manera abrupta y drástica, transforman aquellas representaciones sociales y las significaciones ya construidas de las personas, lugares y las cosas, lo cual deja huellas imborrables en la historia de vida de cada sujeto.

En este sentido, es evidente la afectación que existe en la relación, que se construye entre los sujetos y el espacio físico donde permanecen cotidianamente, otorgando un gran valor a la apropiación del territorio por parte de cada sujeto. Como afirma Osorio (2004), "la territorialidad, en tanto proceso de apropiación de un territorio, se teje por medio de las relaciones y la interacción (sociabilidades) necesarias entre las personas y con el lugar que habitan" (p. 177).

Lamentablemente, cuando un desplazado se ha visto obligado a abandonar su territorio para escapar de la muerte, las sociabilidades entendidas como relaciones e interacciones tejidas dentro del territorio, se van debilitando, como lo afirma Osorio (2004), "las sociabilidades, como parte de un conjunto social determinado, dejan de tener valor real, formar parte y ocupar un lugar dentro de una sociedad determinada y cumplir alli una función social, ello pierde sentido" (p. 177).

$Y$ es precisamente esa ruptura con sus raíces la que persigue a estas familias desarraigadas de Usaquén, y que por lo general son dirigidas por mujeres que asumen el rol de jefes de hogar, a consecuencia de la desintegración de su estructura familiar. Algunas de estas familias pertenecen a la modalidad de Ámbito Familiar de la Secretaría de Distrital de Integración Social (SDIS), cuyo foco de atención son las mujeres gestantes, niños y niñas desde los cero hasta los cuatro años.

Dicha modalidad además de garantizar los derechos de la población atendida y realizar un acompañamiento a madres gestantes, en cuidados prenatales y pautas de crianza, busca potenciar a través de los pilares de la educación, el desarrollo integral de la población infantil.

Gran parte de este trabajo es realizado por maestras de educación inicial, que visitan frecuentemente las familias y trabajan en el seno de sus hogares (Bonilla y Rodríguez, 1989); lo cual hace que su labor se complique en tanto que su formación es en su mayoría de tipo institucional, ligada a un currículo y diseñada para desempeñarla dentro de un aula de clases o en espacios alternativos, pero no en el trabajo con familias y más aún con familias fragmentadas por el desarraigo. 
¡Yo la verdad pensé que era hacer lo mismo que hacía en el jardín, pero en una casa! [...] iCuando me empecé a enfrentar a esa montaña... tenía miedo de hacer las cosas mal, mejor dicho, de no lograr procesos porque era muy diferente de lo que yo venía acostumbrada! (Relato maestra Ámbito Familiar).

Así pues, la maestra de Ámbito Familiar, además de cargar en su maleta el peso de figuras geométricas, cuentos y pinturas, carga en su cabeza múltiples incertidumbres, preguntas sin respuesta, que se convierten en grandes desafíos, ya que debe cumplir con los objetivos de potenciamiento de desarrollo en el niño, sin dejar de lado su entramado histórico, aquel que lo ata a una tierra, a una cultura, a sus raíces.

$Y$ es precisamente el rescate de esas raíces lo que lleva a las maestras a repensar su praxis, encaminada a la reconstrucción de ese tejido social de una crianza en el marco de la guerra; una crianza de la mano de una madre, de una mujer que al igual que la maestra intenta descifrar su nueva realidad, en medio de un diálogo profundo, cercano, de género, de semejanzas y diferencias, que cuestiona el quehacer pedagógico de la maestra.

Dichos cuestionamientos de las maestras y la manera como construian saberes junto con las familias en desarraigo que atendian cotidianamente, fueron analizados durante tres años aproximadamente, a través de una metodología de investigación de tipo cualitativo (Martínez, 1998), donde el abordaje conceptual de las categorías como género, desarraigo y prácticas pedagógicas, además del acercamiento al contexto histórico de guerra en Colombia, se realizó con el fin de construir un marco teórico que permitiera argumentar la temática planteada.

Así a través de la observación, la entrevista semiestructurada (Corbetta, 2007) y los relatos de vida (Cornejo, Mendoza y Rojas, 2008), se avanzó en la investigación, que paulatinamente fue mostrando cómo el diálogo, acompañado de la música, la fotografía, el dibujo y la pintura, tejieron una pedagogía de reconstrucción social.

Por ejemplo, la maestra María Angélica, una de las tres maestras observadas dentro de la investigación, logró acercarse a Lady, una madre desmovilizada de un grupo guerrillero, una mujer que desconfiaba hasta de su propia sombra y quien en principio recibía a la maestra por obligación en la entrada de su improvisada sala.

Día tras día, los encuentros de estas mujeres pasaron de la apretada sala de aquella casa, al espeso verde de un radiante solar, donde la maestra fue descubriendo la realidad de la guerra en los campos colombianos.

Aquella imagen de tranquilidad, cosechas abundantes y atardeceres de ensueño, que la maestra traía a su mente al hablar de campo, se desdibujaba tras las palabras de Lady, que mientras guiaba suavemente la mano de su pequeña hija Nicol pintando un paisaje, revelaba tímidamente los rezagos de una guerra que destruyó su infancia y cambió su rumbo.

Para María Angélica no era fácil estar en casa de una familia desmovilizada, que se camuflaba en la inmensidad de la loma, para ocultar su identidad, huirle al señalamiento y sencillamente intentar sobrevivir.

¡Cuando a uno le dicen la palabra desmovilizado, uno llega ya prevenido, con mucho miedo! ellos son los que mataron, violaron, arremetieron contra otras vidas, como siempre uno poniendo rótulos, desconociendo la otra parte de la historia. (Relato maestra Ámbito Familiar).

Sin embargo, la maestra aceptó el reto y enfrentó sus temores, utilizando entonces las fotografías que adornaban las artesanales paredes del hogar de Nicol, logró trasladarla a su lugar de origen, acompañándola a recorrer su antigua casa impregnada de olor a pescado fresco que traía su abuelo de la Ciénaga de la Cruz, mientras que la niña elaboraba preguntas, identificaba objetos y se anticipaba a los hechos, desarrollando su dimensión comunicativa y fortaleciendo a su vez su identidad a través de su propia historia de vida.

Aunado a ello, también estaban las profundas catarsis de Lady, la madre de Nicol, quien, al rememorar hechos de su vida, descubría con ayuda de María Angélica la valentía con la que había afrontado cada situación, sus fortalezas, talentos y lo mucho que tenía por enseñar.

Por su parte, María Angélica se sentía cada vez más segura de aquellas posibilidades de escucha y diálogo que alimentaba con su trabajo, nutriéndolo 
diariamente, poniendo a flote no solo sus conocimientos, desde sus saberes disciplinarios adquiridos en la academia, sino también sus saberes interiorizados desde la experiencia de ser mujer y madre.

Aquella relación simbiótica, mutualista, que contribuyó a la reconstrucción del tejido social de esta familia, también se reflejó en el trabajo adelantado por la maestra Jazmín, para quien era imprescindible fortalecer la identidad de cada niño y niña, reconstruyendo su historia, sus raíces culturales, a través de una pedagogía que poco a poco se convertía en un bálsamo para aliviar heridas.

Para ello, la maestra retomó una costumbre propia de su natal Tierradentro, convirtiéndola en una herramienta pedagógica de gran validez. Propuso entonces el trueque, con el propósito de intercambiar historias, recoger las voces de la guerra a través de un objeto propio de cada familia, cuyo significado entrañable permitiría trasladarse en el tiempo y volver a sus tierras.

Cada objeto encapsulaba sentimientos y emociones, que a través de un testimonio permitían comprender a ese otro. Un ringlete, por ejemplo, significaba para Yadis, el aire fresco, la arena suave y el olor a chontaduro propio de su región.

A través de este preciado tesoro que Yadis mantenía colgado con una pita en la cabecera de su cama, recordaba las manos amorosas de su tía, sus canciones, sus dichos, los colores que pintaron su infancia. Cada testimonio, reflejaba la valentía, la fuerza y el coraje de la mujer para afrontar las consecuencias de la guerra y continuar haciendo un homenaje a la vida.

La desgastada cobija que envolvía al pequeño Juan Manuel también hacia un homenaje a la vida, pues dentro de sus fibras entrelazadas se escondia la historia de una abuela boyacense que, a punta de maíz y guarapo, había sacado adelante a sus hijos; quienes, por cosas del destino, llevaban consigo las marcas de la guerra a la que se habian unido durante su adolescencia.

Durante estos espacios de remembranza y resignificación, la maestra Jazmín observaba cómo brotaban distintas maneras de leer y entender el conflicto, distintas formas de afrontarlo y múltiples maneras de sacarlo a la luz.
Proponía entonces, después de escuchar atentamente los relatos de cada mujer, plasmar con pinturas, colores y otros materiales lo más significativo de cada testimonio, invitando a los niños y niñas a ser protagonistas de esas historias, a pintar con sus manos los paisajes descritos por sus madres y trasladarse en el tiempo para reconstruir su propia historia.

\section{Conclusiones y recomendaciones del ejercicio investigativo}

La cercanía con las maestras a lo largo de la investigación reveló la enorme dificultad que tuvieron para ejercer su labor desde el seno del hogar de una familia, pues se enfrentaron a un escenario no convencional e intentaron ajustarse a los tiempos establecidos por un hogar, los cuales están sujetos a situaciones propias de la cotidianidad familiar.

Dichas dificultades de las maestras se convierten en una invitación a la academia a pensarse la educación inicial (Cerda, 1996), no solo como un asunto exclusivo de las instituciones educativas, sino pensando que esta traspasa los muros de la escuela y plantea la necesidad de una formación académica que brinde elementos pedagógicos para afrontarla.

Una formación académica que además de permitirle al maestro ejercer su labor desde un espacio familiar, le amplie su visión frente a la realidad que atraviesa el país; una Colombia marcada por la guerra que ha dejado huellas imborrables y que desafía al ámbito educativo para asumir la educación de sus niños y niñas bajo la mirada de maestros que se interesen por hacer lecturas profundas, comprender y proponer respuestas a una población infantil hija del posconflicto.

Son los hijos de esa larga guerra los que han llegado a las periferias de las ciudades para ser acogidos por un sistema que, si bien ha hecho esfuerzos por responder a las necesidades propias de esta población, se ha quedado corto, en cuanto a la reconstrucción del tejido social de estas víctimas.

De ahí la necesidad de que la educación inicial, retome las inquietudes de las maestras que participaron en esta investigación, en torno a su formación 
y las transforme en posibles indicios de lo que podría ser una pedagogía de reconstrucción del tejido social, para la crianza y el desarrollo de una infancia víctima del desarraigo

Es entonces el momento para alimentar, desde la academia, una pedagogía que no solo sane heridas, que alivie dolores y aliente a niños y niñas a descubrir el mundo, escribiendo su propia historia y no la que otros escribieron por ellos, sino que también permita volver a las condiciones materiales y espirituales de una vida digna

Por otra parte, se concluyó dentro de la investigación que, si bien la modalidad de Ámbito Familiar ha brindado la oportunidad de llevar la educación inicial a los hogares de las familias bogotanas en condición de vulnerabilidad, obteniendo grandes resultados, estos podrían favorecer aún más a la población atendida, si dentro de la modalidad se contemplará una educación inicial para el posconflicto. Pues, paradójicamente, gran parte de las familias que se vinculan a esta apuesta educativa se encuentran en desarraigo, motivo por el cual la modalidad les brinda una atención prioritaria, que se traduce en la agilización de la entrega del bono alimentario, creyendo subsanar el problema de manera asistencial.

Por ello, la necesidad explicita que Ámbito Familiar realice una lectura más amplia y le otorgue importancia a las cifras y estadisticas que reposan en sus metas de atención, no solo desde la cobertura, sino también desde la calidad de la atención y el impacto a este tipo de población en desarraigo.

\section{Referencias}

Bonilla, E. y Rodríguez, P. (1989). La investigación en ciencias sociales. Más allá del dilema de los métodos. Bogotá: Editorial Norma.

Castaño, B. (2004). A propósito de los psicosocial y el desplazamiento. En M.N. Bello, Desplazamiento forzado y dinámicas de guerra. Exclusión y desarraigo (pp. 187-195). Bogotá: Universidad Nacional de Colombia.

Centro Nacional de Memoria Histórica, cNmH (2015). Una nación desplazada: informe nacional del desplazamiento forzado en Colombia, Bogotá, CNMH - UARIV.

Cerda, H. (1996). Educación preescolar, historia legislación, currículo y realidad socioeconómica. Bogotá: Magisterio.

Corbetta, P. (2007). Metodología y técnicas de investigación social. Madrid: McGraw-Hill. Recuperado de https://diversidadlocal.files.wordpress.com/2012/09/metodologc3ada-y-tc3a9cnicas-de-investigacic3b3n-social-piergiorgio-corbetta.pdf

Cornejo, M., Mendoza, F. y Rojas, R. (2008). La investigación con relatos de vida: pistas y opciones del diseño metodológico. Psykhe, 17(1), 29-39.

Martínez, M. (1998). La investigación cualitativa etnográfica en educación. México: Trillas. Recuperado de https://es.scribd.com/doc/202652027/La-investigacioncualitativa-etnografica-martinez.

Osorio Pérez, F.E. (2004). Recomenzar vidas, redefinir identidades. Algunas reflexiones entorno de la recomposición identitaria en medio de la guerra y el desplazamiento forzado. En M.N. Bello, Desplazamiento forzado. Dinámicas de guerra exclusión y desarraigo (pp. 175-186). Bogotá: Universidad Nacional de Colombia. 


\section{Diálogo del conocimiento}

En el artículo se analiza la situación que viven las víctimas del desarraigo, quienes no solo afrontan la situación de dejar su territorio, sino que son expuestos a nuevas dinámicas sociales que hacen que se sientan inseguros, amenazados y con minimas oportunidades de obtener trabajo y educación. Así, la autora da a conocer las dinámicas propias de tres maestras de educación inicial encargadas de visitar familias desplazadas o desmovilizadas, lo que hace que su labor se complejice, dado que sus prácticas docentes estaban pensadas para desarrollarse en un salón de clase, mas no en hogares con familias fragmentadas por el desarraigo.

El tema abordado permite la reflexión sobre el papel de la educación en la construcción de nuevos tejidos sociales en las familias víctimas del desarraigo, lo que conlleva la participación activa de las maestras, quienes acompañan el rescate de las raices, costumbres y creencias, a través de estrategias que les brinden seguridad y confianza a quienes forman parte de dichos procesos de formación. El escrito refleja cómo dichas particularidades de las maestras les permiten a estas reflexionar su quehacer pedagógico y repensar sus formas de enseñar, direccionadas a la reconstrucción de identidades formadas en el marco de la guerra.

De esta manera, la autora muestra cómo esos interrogantes de las maestras y la construcción de saberes junto con las familias formaron parte de un proceso de investigación, bajo categorias como género, desarraigo y prácticas pedagógicas, las cuales les dieron voz y protagonismo a las familias y a las maestras. Estas últimas, en especial, se sentían cada vez más seguras de aquellas posibilidades de escucha y diálogo, que alimentaban diariamente con su trabajo, y que ponian a flote no solo sus conocimientos, desde sus saberes disciplinarios adquiridos en la academia, sino también sus saberes interiorizados desde la experiencia de ser mujeres y madres.

Para finalizar, es importante mencionar la relevancia que tienen estos temas, dado que permiten articular situaciones propias del conflicto -como el desplazamiento y la desmovilización-, con prácticas pedagógicas centradas en el diálogo, el reconocimiento de experiencias, la reconstrucción de saberes e identidades; así, es posible visibilizar las dificultades, retos y saberes construidos para emprender la labor docente y aportar a la construcción de una pedagogía para el posconflicto.

Karen Jiménez

Universidad Santo Tomás krenjg0808@gmail.com 